\title{
As recentes tendências da pesquisa em Serviço Social
}

\section{The current tendencies of the research in Social Work}

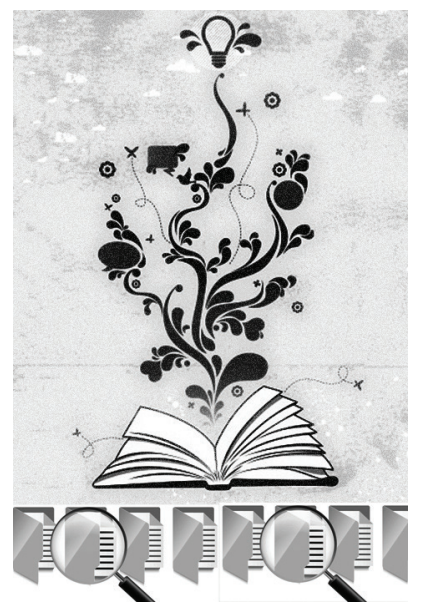

\author{
Jussara Maria Rosa Mendes* \\ Bernadete de Lourdes Figueiredo de Almeida**
}

Resumo: Este artigo analisa as atuais tendências da pesquisa no Serviço Social no contexto do Conselho Nacional de Desenvolvimento Científico e Tecnológico. A partir dos dados levantados pelas representantes do Serviço Social no Comitê de Assessoramento, constata-se a inquestionável relação entre a pesquisa, a produção do conhecimento e a pós-graduação; a vinculação da pesquisa às múltiplas demandas historicamente determinadas pela sociedade capitalista; e as novas tendências do CNPq que denotam pertinência com o Serviço Social: a educação e popularização de ciência e tecnologia e a intersetorialidade.

Palavras-chave: Pesquisa. Produção do conhecimento. Serviço Social.

\begin{abstract}
This article analyzes the current trends of the research in Social Work in the context of Conselho Nacional de Desenvolvimento Científico e Tecnológico (CNPd - National Council for Scientific and Technological Development). From the data collected by the Social Work representatives in the Advisory Committee, it is noted the unquestionable relation among research, production of knowledge and post-graduation; the link between research and the several demands historically determined by the capitalistic society; and the new CNPq trends showing relevance to Social Work: the training and popularization of Science and Technology, as well as intersectoriality.
\end{abstract}

Keywords: Research. Production of knowledge. Social Work.

* Doutora em Serviço Social; docente adjunto do Departamento de Serviço Social da Universidade Federal do Rio Grande do Sul, Brasil; coordenadora do Programa de Serviço Social do Comitê de Assessoramento de Psicologia e Serviço Social (mandato jun./2011-jun./2014).E-mails: jussaramaria.mendes@gmail. com; jussara.mendes@pq.cnpq.br.

** Doutora em Serviço Social; docente associado do Departamento de Serviço Social da Universidade Federal da Paraíba, Brasil; membro do Programa de Serviço Social do Comitê de Assessoramento de Psicologia e Serviço Social (mandato jan./2012-dez./2014).E-mails: blfameida@uol.com.br; bernadete.almeida@ pq.cnpq.br; <http://dx.doi.org/10.1590/0101-6628.002>. 


\section{Introdução}

s bases de sustentação teórico-metodológica do Serviço Social mani-
festam-se sob as mais diversas expressões, sendo a pós-graduação, a
pesquisa e a produção do conhecimento algumas delas.
A proposta deste artigo consiste em traçar um panorama das atuais tendências da pesquisa no Serviço Social, materializadas nas propostas investigativas submetidas pelos pesquisadores dessa área do conhecimento ao $\mathrm{CNPq}$, originadas espacialmente dos programas de pós-graduação brasileiros e na temporalidade dos últimos três anos (2011-2013).

Em face desse recorte espacial e temporal, levantam-se as seguintes questões analíticas: As recentes propostas de pesquisa da área do Serviço Social encaminhadas ao CNPq revelam as suas atuais tendências? As pesquisas expressam ainda a hegemonia da "base de sustentação funcional-ocupacional" do Serviço Social, o que lhe confere especificidade ou particularidade histórica? As pesquisas analisam objetos pertinentes aos fundamentos do Serviço Social e demais categorias tão caras à profissão, como "questão social", políticas sociais, processo de trabalho, entre outras?

Decerto, tratar sobre pesquisa em determinada área do saber pressupõe relacioná-la ao seu processo de acúmulo científico e tecnológico que se anuncia na produção do conhecimento, gerada sobremaneira na academia, sobretudo nos programas de pós-graduação.

Essa constatação permite atinar que a maior parte da produção do conhecimento materializada na publicação de livros, artigos e capítulos de livros, além das teses e dissertações, deriva de pesquisas científicas originadas dos docentes e alunos dos programas de pós-graduação stricto sensu na área do Serviço Social.

O interesse em investigar a pesquisa no Serviço Social e a sua relação com a produção do conhecimento e a pós-graduação é recente no país. Advém da criação dos primeiros programas de pós-graduação na década de 1970 e a inserção dos pesquisadores do Serviço Social nas agências de fomento brasileiras (CNPq e Capes) nos anos de 1980. Assim, se expressa Prates (2013, p. 213):

O processo de amadurecimento do Serviço Social no Brasil, uma profissão ainda muito jovem, se comparada a profissões milenares, vem se tornando consistente na pesquisa e produção de conhecimentos a partir do final do século XX. É possível afirmar que a pesquisa e a produção de conhecimentos delas decorrentes constituíram 
um verdadeiro divisor de águas no processo de consolidação do acúmulo simbólico do Serviço Social nos últimos quarenta anos. No momento em que os programas de pós-graduação em Serviço Social se conformam no país e que se amplia uma produção de conhecimentos mais densa na área, a profissão ganha um novo estatuto.

A criação dos programas de pós-graduação como fator impulsor da produção do conhecimento e, consequentemente, da pesquisa no Serviço Social tem sido tema recorrente na literatura do Serviço Social, como: Setúbal (1995), Faria (2003), Silva e Silva (2004), Kameyama (2004), Silva e Silva e Carvalho (2005 e 2007), Lara (2007 e 2008), Sposati (2007), Bourguignon (2005, 2007 e 2008), dentre outros autores.

Guerra (2011, p. 126) ressalta a importância da pós-graduação sob inspiração crítica do Serviço Social "que hoje detém hegemonia na produção do conhecimento e da pesquisa, responsável pela renovação da imagem profissional e por tornar o Serviço Social contemporâneo de seu tempo, colocando-o como interlocutor reconhecido no campo das ciências sociais".

Em virtude da sua inserção concreta no real, o Serviço Social gera uma rica contribuição para a teoria social. "Entendo que já temos maturidade para melhor explicitar 'eixos temáticos' com mais precisão, de modo a orientar e dar rumos mais concretos para a pesquisa em Serviço Social” (Sposati, 2007, p. 24).

Embora se reconheça a existência de avanços na interlocução entre a pós-graduação, a produção do conhecimento e a pesquisa no Serviço Social, muito ainda se tem a trilhar a partir dos desafios e das dificuldades que perpassam o Serviço Social e a relação com a dinâmica das instituições de fomento à pesquisa no Brasil.

\section{Análise das atuais tendências da pesquisa no Serviço Social a partir das demandas propostas ao $\mathrm{CNPq}$}

O desenvolvimento de pesquisas no Serviço Social não difere das demais áreas do saber, deriva da atuação predominantemente acadêmica de docentes e alunos da pós-graduação stricto sensu, embora se reconheça a relevância das produções que dimanam dos trabalhos de conclusão do curso de graduação decorrentes de pesquisas realizadas na realidade dos campos de estágio supervisionado, bem como dos trabalhos monográficos dos cursos de especialização que, grosso modo, analisam a intervenção profissional nas unidades programáticas das políticas sociais. 
No conjunto das pesquisas, distinguem-se as de caráter individual, grupal e institucional desenvolvidas por docentes e pesquisadores, com financiamento ou não dos órgãos de fomento, como Capes, $\mathrm{CNPq}$, fundações de pesquisas em nível estadual, nacional e internacional.

A inserção da área do Serviço Social no CNPq é relativamente recente, aproximadamente trinta anos, identificado como um programa que juntamente com Psicologia compõe o Comitê de Assessoramento (CA-PS) com representantes dessas duas áreas do saber, sendo dois do Serviço Social e seis da Psicologia.

Os representantes das áreas que compõem o Comitê são escolhidos "periodicamente pelo Conselho Deliberativo (CD), com base em consulta feita à comunidade científico-tecnológica nacional e têm a atribuição, entre outras, de julgar as propostas de apoio à pesquisa e de formação de recursos humanos" (CNPq, 2014, p. 1).

O CA-PS juntamente com mais outros seis comitês de assessoramento (Difusão Científica, História, Artes, Ciência da Informação e Comunicação, Filosofia I, Filosofia II e Letras e Linguística) integra a Coordenação do Programa de Pesquisa em Ciências Humanas e Sociais (COCHS), vinculada à Diretoria de Engenharias, Ciências Exatas e Humanas e Sociais (DEHS) do CNPq.

O programa de Serviço Social tem concorrido aos seguintes editais e chamadas públicas: bolsas especiais nas modalidades no país em nível de pós-graduação (doutorado Pleno - GD e doutorado sanduíche no país - SWP) e em nível de pesquisa (pós-doutorado júnior - PDJ e pós-doutorado sênior - PDS) e exterior em nível de pós-graduação (doutorado pleno - GDE e doutorado sanduíche SWE) e em nível de pesquisa (pós-doutorado - PDE) e estágio sênior (ESN), todas essas modalidades com cronogramas 1, 2 e 3; além da bolsa de produtividade em pesquisa (PQ); bolsas de apoio técnico (AT), bolsas de iniciação científica (IC), o edital universal com 3 faixas de financiamento; ciências humanas, sociais e sociais aplicadas (financiamento de pesquisa), e apoio a eventos científicos (Arc) - fases 1 e 2 .

As propostas submetidas ao CA-PS concorrem anualmente e são atendidas a partir de dois parâmetros: a quantidade de demandas encaminhadas aos programas (Serviço Social e Psicologia) e os recursos orçamentários disponibilizados pelo CNPq. Em outras palavras: para cada edital ou chamada pública, esse órgão estabelece um montante de recursos financeiros a ser rateado entre os programas, cujo critério de demandas atendidas dependerá da quantidade de propostas submetidas. 
Em torno desse critério, fragilizam-se os menores programas - como o de Serviço Social - por possuírem menor número de pesquisadores bolsistas Pq e baixa demanda. Constatação que se comentará mais adiante.

A análise a ser realizada acerca das atuais tendências da pesquisa no Serviço Social a partir das demandas submetidas ao CNPq corresponde ao período de agosto de 2011 a julho de 2014, compreendendo aos mandatos das professoras Denise Bontempo de Carvalho Birche (jan./2009-dez./2011), Jussara Maria Rosa Mendes (jul./2011-jun./2014) e Bernadete de Lourdes Figueiredo de Almeida (jan./2012-dez./2014).

As análises possibilitaram avaliar que fatores contribuem para que ocorra a diferença existente entre as propostas submetidas pelos pesquisadores e as recomendadas pelo programa de Serviço Social a partir dos recursos financeiros disponibilizados pelo CNPq.

Em termos quantitativos, destaca-se a tendência da pesquisa do Programa de Serviço Social no contexto do CNPq: um panorama introdutório sobre a real situação da pesquisa do SS no CNPq que expõe a frágil relação entre demandas recebidas e recomendadas. Os dados permitem comprovar a aproximação relacional existente entre o número de demandas recebidas e o montante de recursos liberados pelo CNPq. Portanto, a lógica gerencial de distribuição de recursos financeiros por programas de pesquisa está imbricada à quantidade de demandas encaminhadas. Trata-se de uma lógica competidora: o programa que apresenta mais demandas é o que mais recebe recursos financeiros.

Para elucidar essa constatação, tomam-se como exemplo as demandas encaminhadas e os recursos disponibilizados pelo CNPq para o CA-Psicologia e Serviço Social na chamada pública MCTI/CNPq/MEC/Capes (Ciências Humanas, Sociais e Sociais Aplicadas) referente aos anos de 2012 e 2013, conforme Quadro 1 a seguir:

Quadro 1. Relação entre demandas e recursos financeiros das chamadas MCTI/CNPq/MEC/ Capes n. 18/2012 e n. 43/2013

\begin{tabular}{|l|c|c|c|c|c|c|}
\hline \multirow{2}{*}{ CA-PS } & \multicolumn{2}{|c|}{2012} & \multirow{2}{*}{$\begin{array}{c}\text { Per } \\
\text { capita }\end{array}$} & \multicolumn{2}{|c|}{$\mathbf{2 0 1 3}$} & \multirow{2}{*}{$\begin{array}{c}\text { Per } \\
\text { capita }\end{array}$} \\
\cline { 2 - 3 } & Número & RS & Número & R\$ & \\
\hline Psicologia & 130 & $658.000,00$ & $5.061,53$ & 116 & $721.064,17$ & $6.216,07$ \\
\hline Serviço Social & 28 & $141.125,00$ & $5.040,18$ & 25 & $112.106,45$ & $4.484,25$ \\
\hline
\end{tabular}

Fonte: CNPq. 
A apresentação desses dados permite realizar duas dentre outras análises: a primeira trata da diferença per capita entre os dois programas que compõem o mesmo Comitê de Assessoramento, acentuando-se essa diferença no ano de 2013; a segunda revela que enquanto ocorreu um crescimento orçamentário dos recursos destinados ao Programa de Psicologia, os do Serviço Social decresceram, como indicam os valores per capita entre os anos de 2012 e 2013.

O mais surpreendente na desigual destinação de recursos para esses dois Programas é que em ambos houve uma redução de demandas de um ano para outro. Mas enquanto o Programa de Serviço Social foi atingido pela diminuição de recursos em face do abaixamento de demandas, deu-se o contrário com o Programa de Psicologia: mesmo com a demanda reduzida de um ano para outro, recebeu mais recursos financeiros entre os dois últimos anos (Mendes e Almeida, 2013a).

Essa realidade dual entre Serviço Social e Psicologia se reproduz em todos os editais e chamadas. Desse modo, perpetua-se uma grande fragilidade da área junto ao $\mathrm{CNPq}$, marcado pela redução gradativa de demandas encaminhadas pelos pesquisadores, o que gera um círculo vicioso: parcos recursos financeiros disponibilizados determinam escassas demandas recomendadas. Nessa lógica desigual, com a definição de recursos para as áreas definidas a partir das demandas, somada ao descrédito dos pesquisadores na aprovação de seus projetos, expõe-se a situação de vulnerabilidade da área junto ao CNPq.

De modo a confirmar essa constatação, segue o Quadro 2 que apresenta os dados pertinentes à Chamada MCTI/CNPq/MEC/Capes n. 43/2013. Nesses dados são alistados: os recursos integrais disponibilizados pela Coordenação do Programa de Pesquisa em Ciências Humanas e Sociais (que possui seis Comitês de Assessoramento), os recursos destinados ao Comitê de Assessoramento de Psicologia e Serviço Social e ao Programa de Serviço Social.

Quadro 2. Recursos financeiros da chamada MCTI/CNPq/MEC/Capes n. 43/2013

\begin{tabular}{|l|c|c|}
\hline \multicolumn{1}{|c|}{ Recursos disponibilizados } & Valor (R\$) & $\%$ \\
\hline Chamada MCTI/CNPq/MEC/Capes n. 43/2013 & $8.000 .000,00$ & 100 \\
\hline $\begin{array}{l}\text { Coordenação do Programa de Pesquisa em Ciências } \\
\text { Humanas e Sociais (COCHS) }\end{array}$ & $2.282 .391,54$ & 28,52 \\
\hline Comitê de Assessoramento de Psicologia e Serviço Social & $721.064,17$ & 9,01 \\
\hline Programa de Serviço Social & $112.106,45$ & 1,4 \\
\hline
\end{tabular}

Fonte: $\mathrm{CNPq}$. 
A leitura desses dados aponta a insignificância orçamentária disponibilizada para o Programa de Serviço Social, cuja participação corresponde a 1,4\% do montante de recursos. Ao correlacionar os recursos financeiros disponibilizados para o Programa de Serviço Social com os recursos liberados para a COCHS, à qual esse programa se vincula, constata-se que corresponde a $4,91 \%$; e ao comparar os recursos concedidos para esse Programa com os recursos indicados para o Programa de Psicologia, com o qual integra o mesmo Comitê de Assessoramento, depara-se com o percentual de $15,5 \%$.

O aumento expressivo do atendimento das demandas do Programa de Psicologia pelo CNPq deriva da amplitude dessa área do conhecimento, que conta com 73 programas de pós-graduação enquanto o Serviço Social tem 31; além de ter 311 pesquisadores de Produtividade em Pesquisa (PQ), enquanto são 71 no Serviço Social. Em termos quantitativos tem-se uma relevante diferença.

Apoiada na perspectiva da lógica produtivista adotada pelas Agências de Fomento, a alternativa para atenuar essa diferença em médio prazo é o Programa de Serviço Social investir mais na expansão da Pós-Graduação stricto sensu e ampliar significativamente a demanda reprimida de pesquisadores qualificados para provocar o crescimento da concessão de bolsas PQ (Mendes e Almeida, 2013a).

Outro dado concreto que comprova a fragilidade da pesquisa do Serviço Social no CNPq em comparação com o Programa de Psicologia e a chamada pública de bolsas de produtividade em pesquisa 2013. Do total de 245 propostas encaminhadas ao Comitê de Assessoramento de Psicologia e Serviço Social (CA-PS), 203 demandas destinam-se ao Programa de Psicologia e 42 ao do Serviço Social.

Trata-se de uma significativa diferença de demandas entre os dois programas que compõem o mesmo comitê, uma vez que o Programa do Serviço Social recebeu apenas $17,1 \%$ do total das propostas submetidas em relação ao de Psicologia. Assim, a frágil realidade do Programa de Serviço Social tende a se eternizar, caso não se reverta esse quadro expressado pelo reduzido número de pesquisadores (PQ) existentes e de poucos demandantes de novas propostas ao Programa de Bolsas de Produtividade do CNPq (Mendes e Almeida, 2013b).

A título de ilustração, analisa-se de forma comparativa a concessão de bolsas PQ destinadas ao comitê de assessoramento de Psicologia e Serviço Social. Em 2012, o Programa de Psicologia concentrou 80\% dessas propostas ao CA-OS; assim, o Serviço Social ficou com 20\%. Para 2013, do total de 117 bolsas concedidas para o CA-OS, o Programa de Psicologia recomendou 129 para uma cota de 104 bolsas derivadas do término de vigência (fev. 2014); o Programa de Serviço Social reco- 
mendou 33 para uma cota de treze bolsas. A comparação das cotas de bolsas PQ entre os dois programas corresponde a $88,8 \%$ do total para a Psicologia, cabendo $11,2 \%$ ao Serviço Social.

Trata-se de uma diminuição expressiva e gradativa das cotas de PQ para o Programa de Serviço Social: enquanto em 2012 a concessão de bolsas foi de $20 \%$ no que se refere à Psicologia, em 2013 a concessão de bolsas caiu para 11,2\%. Portanto, mantém-se e reforça-se a mesma lógica desigual (na relação demanda versus concessão) entre os dois programas que compõem o mesmo comitê (Mendes e Almeida, 2013b).

Em termos qualitativos, destaca-se outra tendência da pesquisa do Serviço Social no âmbito do CNPq. Trata-se das áreas e subáreas de investigação do Programa de Serviço Social. Tomando como referência as chamadas de bolsas de produtividade em pesquisa nos anos 2012 e 2013, atesta-se a predominância da área Serviço Social Aplicado - que também contempla as políticas sociais (com suas subáreas) — sobre a de Fundamentos em Serviço Social, como apresenta a Tabela 1 a seguir:

Tabela 1. Número de propostas estratificadas por subáreas do Serviço Social no CNPq referentes às chamadas $P Q-2012$ e 2013. Brasília: 2012-2013

\begin{tabular}{|l|c|c|c|c|}
\hline \multicolumn{1}{|c|}{ Subáreas do Cnpq } & $\mathbf{2 0 1 2}$ & $\mathbf{2 0 1 3}$ & Número & \% \\
\hline Serviço Social aplicado & 15 & 14 & 29 & 31,5 \\
\hline Fundamentos em Serviço Social & 19 & 13 & 32 & 34,8 \\
\hline Serviço Social da Saúde & 5 & 3 & 8 & 8,7 \\
\hline Serviço Social da Educação & 3 & 6 & 9 & 9,8 \\
\hline Serviço Social do Trabalho & 6 & 4 & 10 & 10,9 \\
\hline Serviço Social da Habitação & 1 & 2 & 3 & 3,3 \\
\hline Serviço Social do Menor & 1 & - & 1 & 1,0 \\
\hline Total & $\mathbf{5 0}$ & $\mathbf{4 2}$ & $\mathbf{9 2}$ & $\mathbf{1 0 0}$ \\
\hline
\end{tabular}

Fonte: $\mathrm{CNPq}$.

Em princípio, chama-se a atenção para o obsoletismo dessa estratificação do conhecimento que não atende às atuais demandas postas ao Serviço Social, além 
de derivar da tradição conservadora da divisão positivista do saber. Além disso, esses dados revelam a predominância das propostas investigativas sobre as políticas sociais e a redução na área dos fundamentos do Serviço Social.

Trata-se da adoção arcaica da divisão das áreas e subáreas (conhecida como "árvore") do conhecimento do Serviço Social nas agências de fomento, como CNPq e Capes. Em face dessa inadequada divisão, em todos os relatórios técnicos elaborados pelo comitê de assessoramento tem se registrado tanto a discrepância da nomenclatura como acusado a divisão positivista que essa "árvore" insere entre o pensar e o agir, quando ambos derivam dos mesmos fundamentos históricos e teórico-metodológicos da sociedade que embasa o conhecimento. No Serviço Social,

a compreensão teórico/metodológica da realidade, fundada no acervo intelectual que se constituiu a partir das principais matrizes do pensamento social e de suas expressões nos diferentes campos do conhecimento humano, é processo que se constrói na interlocução com o próprio movimento da sociedade. (Yazbek, 2006, p. 2)

Nos dados da Tabela 1, a predominância das análises em torno das políticas sociais - nas quais corporificam os espaços sócio-ocupacionais do assistente social - conforma-se como uma tendência da pesquisa e, obviamente, da produção do conhecimento (livros, artigos, teses, dissertações) e dos programas de pós-graduação (áreas de concentração e linhas de pesquisa) no Serviço Social. Essa constatação tem sido analisada por autores, como Simionatto (2005), Yazbek (2006), Iamamoto (2007), Baptista (2009), Guerra (2013, p. 39). Esta última assevera

a influência do pragmatismo no Serviço Social que, como representação ideal da imediaticidade do mundo burguês, influencia a profissão do ponto de vista prático-profissional, teórico e ideopolítico, constituindo-se em um desafio a ser enfrentado por todos os segmentos da categoria.

Mesmo embalada por essa imediaticidade, engendrada pela sociedade burguesa, as primeiras décadas de pesquisas e produções do conhecimento na área do Serviço Social privilegiavam a análise de objetos retirados dos fundamentos (formação profissional, ensino, prática, estágio), conforme indica o artigo "Produção científica do Serviço Social no Brasil", de autoria de Ammann (1984). Essa tendência 
é ratificada no artigo "A trajetória da produção de conhecimentos em Serviço social: avanços e tendências", de Kameyama (1998), que avalia essa produção ao longo do período de 1975-1997.

Decerto, a predominância das análises sobre as políticas sociais e o arrefecimento na pesquisa dos objetos identificados como fundamentos do Serviço Social ocorre a partir dos anos 2000 .

Toma-se como referência o artigo "Trinta anos da revista Serviço Social \& Sociedade: contribuições para a construção e o desenvolvimento do Serviço Social no Brasil", de Silva e Silva (2009, p. 610-611) que realiza uma pesquisa em torno das temáticas, objeto dos artigos publicados no referido periódico. No período de 2000-09, a citada autora catalogou 523 categorias temáticas, sendo 72 em fundamentos do Serviço Social (formação profissional, prática, projeto político-pedagógico, teoria, metodologia, ensino, currículo, pesquisa, ética, organização profissional etc.) e 451 em políticas públicas/políticas sociais e demais temáticas relacionadas (questão social, família, idoso, cidade, Estado, sociedade civil, trabalho, gênero, pobreza, terceiro setor, entre outras).

A análise investigativa no Serviço Social assenta-se nas especificidades dessa área do conhecimento, como afirma Iamamoto (2007, p. 210), por derivar das "particularidades atribuídas à profissão na divisão social e técnica do trabalho e suas implicações para a interpretação e condução do trabalho do assistente social na atualidade".

Outra tendência refere-se ao foco das pesquisas do Serviço Social, vinculado às múltiplas demandas sociais historicamente determinadas pela sociedade capitalista. “[...] os objetos de investigação do Serviço Social emergem de uma realidade concreta e estabelecem suas mediações numa sociedade que se produz e reproduz por meio de contradições inconciliáveis" (Lara, 2007, p. 73).

Essa tendência desenvolve-se na contramão do interesse investigativo dos órgãos de fomento. Como se registra em trecho do discurso de Marco Antônio Raupp, então ministro do Desenvolvimento Científico e Tecnológico durante o Seminário de Avaliação das Bolsas de Produtividade em Pesquisa, promovido pelo CNPq junto aos representantes de comitês de assessoramento de todas as áreas do conhecimento, na cidade de Brasília, em abril de 2013:

Nós queremos incrementar a qualidade da ciência brasileira. Nossa preocupação é com a demanda e modernização da sociedade [...]. Temos áreas que obtiveram grandes 
avanços nos últimos anos, como agronegócios, petróleo e gás, aeronáutica, cosméticos, automação bancária. Precisamos disseminar esse desenvolvimento para outras áreas e este Seminário pode contribuir para isso. (CNPq, apud Mendes e Almeida, 2013c, p. 5-6)

No supracitado Seminário de Avaliação, o presidente do CNPq Glaucius Oliva elencou as principais dificuldades para o avanço da ciência brasileira:

[...] a falta de qualificação, relevância e impacto dos projetos; a necessidade de ampliação do nível de inovação e das patentes registradas; a atração de talentos para contribuir principalmente na qualificação da mão de obra nacional; a multidisciplinaridade das propostas apresentadas e a sustentabilidade agregada às iniciativas. (CNPq, apud Mendes e Almeida, 2013c, p. 6-7)

Seguramente, esses discursos traduzem enormes desafios para as áreas do saber que não priorizam ou não adotam tais perspectivas. Para essas áreas, é impensável discorrer sobre desenvolvimento científico e tecnológico se este não estiver articulado às necessidades da sociedade, ao desenvolvimento humano. A avaliação da produção científica não deve se limitar a parâmetros objetivos como o impacto nacional dessa produção com a média mundial, o ranking da produção científica e tecnológica brasileira no contexto mundial, a dependência tecnológica do país em relação aos demais, o número de patentes licenciadas, entre outros indicadores produtivistas (Mendes e Almeida, 2013c).

Nessa perspectiva, a centralidade que o conhecimento detém na sociedade global do século XXI torna-se um abissal desafio, sobretudo na realidade brasileira, marcada profundamente por inúmeras desigualdades, desde o acesso ao atendimento das necessidades básicas à inserção às mais diversas formas do conhecimento.

Para Sérgio Adorno, um dos conferencistas do referido Seminário, há singularidades no tocante à qualidade do impacto do conhecimento, uma vez que os objetos são singulares dentre as áreas do saber.

Os impactos devem ser vistos na dimensão de sujeitos e objetos que dialogam; não se separam. Logo, os impactos do conhecimento envolvem naturezas que derivam da objetividade e da subjetividade (quantidade e qualidade). Deve-se considerar que nem todos os objetos são materiais, há a linguagem, as ideias, as imagens, as 
reflexões, enquanto objetos científicos imateriais [...]. (Adorno, apud Mendes e Almeida, 2013c, p. 7-8)

Segundo esse autor, a pesquisa nas Ciências Humanas e Sociais, Letras e Artes envolve um processo complexo: primeiro problema: como avaliar o impacto de valor de uma comunidade? segundo problema: a contribuição das Ciências Humanas e Sociais não tem impacto no desenvolvimento científico e tecnológico, mas impacta na qualidade de vida, impacta na desigualdade social; terceiro problema: nas Ciências Humanas e Sociais há uma gama de tradições derivadas, sobretudo, da Filosofia e da Sociologia. Há, portanto, uma diversidade de tradições. Assim, como adotar apenas a investigação produtivista para o desenvolvimento científico e tecnológico? (Mendes e Almeida, 2013c).

No entendimento de Adorno, as pesquisas artesanais, predominantes nas Ciências Humanas e Sociais, já convivem com as áreas tecnológicas, mas há de se considerar o problema de linguagem dessas ciências. Para as humanidades: o que é um artigo? Um livro? Um capítulo de livro? Não são produções iguais se comparadas com as demais áreas do conhecimento. Há um problema de linguagem nas humanidades porque não há uma formalização (técnica) como nas demais áreas. Por exemplo: em periódicos da área das humanidades, as análises são verdadeiras peças literárias. O que de fato deriva da pesquisa? Esse é um dos grandes desafios da área das humanidades (Mendes e Almeida, 2013c).

No caso da pesquisa em Serviço Social, os desafios avolumam-se como: o número reduzido de pesquisadores vinculados às agências de fomento nacionais e internacionais; as propostas de pesquisa tipificadas majoritariamente como estudo de caso, portanto, com unidade investigativa restrita; as dificuldades em elaborar projetos de pesquisas com domínio teórico-metodológico, uma vez que parte significativa das propostas apresenta intenso cariz interventivo em face da especificidade da área; a baixa circulação da produção do conhecimento da área limitado aos periódicos dos programas de pós-graduação, muitas vezes de forma endógena, entre outros.

De modo a balizar um desses desafios apontados, apresentam-se, a seguir, os dados referentes à produção científica dos pesquisadores do CNPq na área do Serviço Social, conforme registro no Curriculum Lattes. Esses dados derivam da reavaliação das bolsas de produtividade em pesquisa, realizada trienalmente pelo CNPq. 
Tabela 2. Tipos de produção científica (bibliográfica e técnica) dos pesquisadores do Serviço Social por categorias de bolsas PQ - Brasília, abril 2010-2013

\begin{tabular}{|l|c|c|c|c|c|c|}
\hline \multirow{2}{*}{ Tipos de produção } & \multicolumn{2}{|c|}{ Categoria P0 1 } & \multicolumn{2}{c|}{ Categoria P0 2 } & \multicolumn{2}{c|}{ Total } \\
\cline { 2 - 8 } & Número & Per capita & Número & Per capita & Número & Per capita \\
\hline Artigos & 330 & 10,3 & 242 & 5,8 & 572 & 7,7 \\
\hline Livros publicados & 149 & 4,7 & 41 & 0,9 & 190 & 2,6 \\
\hline Capítulos de livro & 416 & 13 & 270 & 6,4 & 686 & 9,3 \\
\hline Livros organizados & 116 & 3,6 & 43 & 1,1 & 159 & 2,1 \\
\hline $\begin{array}{l}\text { Trabalhos completos } \\
\text { publicados em eventos }\end{array}$ & 529 & 16,5 & 554 & 13,2 & 1.083 & 14,6 \\
\hline $\begin{array}{l}\text { Apresentação de } \\
\text { trabalhos/palestras }\end{array}$ & 1.181 & 36,9 & 707 & 16,8 & 1.888 & 25,5 \\
\hline Total & $\mathbf{2 . 7 2 1}$ & $\mathbf{8 5 , 0}$ & $\mathbf{1 . 8 5 7}$ & $\mathbf{4 4 , 2}$ & $\mathbf{4 . 5 7 8}$ & $\mathbf{6 1 , 8}$ \\
\hline
\end{tabular}

Fonte: CNPq.

Ao analisar a produção científica dos pesquisadores $\mathrm{PQ}$, da área do Serviço Social depara-se com enorme dificuldade de legitimar os atuais critérios avaliativos da área, posto que a maioria das áreas de conhecimento julga a produção dos seus pesquisadores bolsistas a partir de um único critério avaliativo: a produção de artigos em periódicos com fator de impacto. Adotam o índice $H$ (ou índice de citações), definido como uma proposta para quantificar a produtividade e o impacto de cientistas, baseando-se nos artigos (papers) mais citados (Mendes e Almeida, 2013c).

Durante o referido processo de reavaliação trienal das bolsas de produtividade em pesquisa, os membros do Comitê verificaram que são limitadas as áreas do conhecimento - entre elas, a de Serviço Social — que ainda consideram como critérios inclusivos de avaliação da produção científica dos seus pesquisadores bolsistas os "trabalhos completos publicados em eventos" e as "apresentações de trabalhos/resumos e palestras (ou conferências)". Esse tipo de produção na área do Serviço Social representa dois terços da produção científica dos pesquisadores (Mendes e Almeida, 2013c).

Esses, entre outros desafios, fazem com que a pesquisa no Serviço Social se coloque de forma subalterna e minoritária no mundo da produção do conhecimento científico, dominado pela inovação tecnológica imposta pelo atual capital 
corporativo. Porém o grande desafio é estabelecer uma ampla reflexão e traçar estratégias que atendam as demandas da área.

Ainda no tocante às discussões levantadas no Seminário promovido pelo CNPq, registra-se a emersão de duas outras tendências adotadas por esse órgão de fomento que podem ser profícuas para a pesquisa na área do Serviço Social. A primeira refere-se ao novo critério adotado para avaliação das pesquisas encaminhadas ao CNPq, denominado Educação e Popularização de C \& T. Nesse enfoque, reconhece-se que a área do Serviço Social tem potencialidade investigativa de inserção no referido critério avaliativo, uma vez que grande parte dos bolsistas apresenta em seu Curriculum Lattes número significativo de eventos organizados, livros publicados e organizados, palestras proferidas, matérias em jornais, revistas e TV, entre outros mecanismos de difusão científica. No entanto, ainda é pouco registrado pelos pesquisadores da área como indicador de Educação e Popularização de C \& T.

E a outra nova tendência que começa a ser delineada no CNPq é a perspectiva da interdisciplinaridade na pesquisa. Nesse sentido, ainda em 2013, os comitês de assessoramento elaboraram um documento, a pedido do CNPq, sobre a perspectiva e as possibilidades de interdisciplinaridade na pesquisa.

Os representantes do Serviço Social no CA-PS assim se posicionaram quanto à perspectiva conceitual de interdisciplinaridade:

A perspectiva de trabalho interdisciplinar é uma exigência intrínseca do próprio saber, como um caminho novo para exploração mais intensa dos problemas, da análise e da gestão e intervenção social, bem como estratégia efetiva para o deslindamento de seu significado político. Essa perspectiva indica um caminho possível de amadurecimento entre as áreas, considerando a incompletude que cada uma invariavelmente impregna. A interdisciplinaridade se define como um procedimento de copropriedade, de interação e interlocução que exige um diálogo permanente entre os sujeitos envolvidos em determinadas ações que demandam respostas, muitas vezes imediatas. Significa um alargamento do saber e a expansão e flexibilização no âmbito do conhecimento. (Mendes e Almeida, 2013d, p. 1)

Nesse entendimento, o Serviço Social é uma das áreas do conhecimento que trabalha em linha direta com as diferenciadas expressões da questão social e possui na mesma um campo qualificado de atuação direta. Caracteriza-se como profissão que atua diretamente na interdisciplinaridade, contribuindo, dessa forma, para a 
construção coletiva do conhecimento no interior do conjunto das ciências sociais e humanas (Mendes e Almeida, 2013d).

Os representantes de Serviço Social no CA-PS apreendem que essa área do conhecimento compõe com outras que possuem diferentes correntes teórico-metodológicas tanto internamente como também entre si. Nessa acepção, o exercício da interdisciplinaridade insurge como mecanismo capaz de lidar com essas diferenças. O desafio é converter essa inter-relação em saldo e não em débito para o profissional, para a categoria, para a equipe de trabalho, para o usuário e para a política universal de direitos - eixo comum entre todas as profissões. Seja em qualquer subárea de atuação — saúde, educação, assistência social, previdência, dentre outras - lidar com o conteúdo do outro e respeitá-lo como digno de troca faz parte do princípio da interdisciplinaridade (Mendes e Almeida, 2013d).

A interlocução do Serviço Social com outros saberes parte da contextualização em que a pesquisa está inserida, sobretudo quando essa inter-relação se processa pela via das políticas sociais.

Ademais, as pesquisas multi ou interdisciplinares são consideradas quando contemplam conhecimentos que também se articulam com os fundamentos do Serviço Social. Nesse caso, tais pesquisas podem ser acolhidas pela área do Serviço Social e precisam ser avaliadas com procedimentos e critérios adequados às suas características. Mas construir esses procedimentos e critérios ainda é uma tarefa em curso na área.

Para o CA-Serviço Social pesquisas multi/interdisciplinares são necessárias, como caminho possível de amadurecimento entre as áreas, portanto merecem ser apoiadas. [...] A avaliação desses projetos de pesquisa requer condições operacionais novas, internas e próprias a cada $\mathrm{CA}$, além de um padrão de financiamento que contemple essas novas demandas. (Mendes e Almeida, 2013d, p. 4)

Decerto, há outras tendências que perpassam a pesquisa em Serviço Social já amplamente levantadas em produções anteriores, tais como: Setubal (1995 e 2007), Kameyama (1998, 2004a e 2004b), Faria (2003), Silva e Silva (2004), Abreu (2007), Sposati (2007), Bourguignon (2007 e 2008), Lara (2007 e 2008), Moraes (2013), dentre outros autores. Desse modo, neste artigo, não se pretende esgotar a discussão sobre as tendências da pesquisa na área do Serviço Social nem tampouco no contexto do $\mathrm{CNPq}$, pois embora recente, a pesquisa nessa área espraia-se entre outras áreas do saber e agências de fomento nacional e internacional. 
O reconhecimento da pesquisa no Serviço Social na institucionalidade científica no CNPq como área de conhecimento e na CAPES como área de produção de conhecimentos foi e ainda, de certa forma, o é (quanto a estatuto e a recursos para pesquisa) resultante de inúmeras lutas. Agências de fomento como a paulista Fundação de Amparo à Pesquisa do Estado de São Paulo (Fapesp), a internacional Fundação Ford, entre outras já incorporam o financiamento de pesquisa no campo do Serviço Social. (Sposati, 2007, p. 18)

Nesse sentido, retomam-se as questões levantadas no início deste artigo. O avanço da pesquisa no Serviço Social é afirmado por todos seus autores que escrevem sobre esse assunto, sobretudo a relação existente entre a pesquisa e a hegemonia da "base de sustentação funcional-ocupacional" do Serviço Social, traço que lhe confere especificidade ou particularidade histórica. Nesse sentido, para os assistentes sociais na atual conjuntura, "a pesquisa e o esclarecimento teórico tornaram-se seus principais meios de trabalho, pois é a partir da sistematização da realidade social que o profissional tem condições de agir com mais segurança e dar possíveis respostas que sejam aceitas pela objetividade social (Lara, 2007, p. 73).

As atuais subáreas, nas quais as propostas de pesquisa se enquadram, indicam objetos pertinentes aos fundamentos do Serviço Social e demais categorias tão caras à profissão, como questão social, processo de trabalho, políticas sociais - esta temática atualmente predominante —-, entre outras.

\section{Considerações finais}

Conforme este artigo foi iniciado, é impensável a pesquisa científica fora dos espaços da pós-graduação, geradora da produção do conhecimento. $\mathrm{Na}$ área do Serviço Social não ocorreu de forma diferente das demais. Iniciadas nos anos 197080, no Brasil, a pesquisa, a produção de conhecimento e a pós-graduação andam juntas. Trata-se de um processo de construção derivado do corpo profissional que passou a produzir a sua acumulação teórica. Embora essa produção se apresente desigual, segundo Netto (2006, p. 151-152),

ela engendrou uma massa crítica considerável, que permitiu à profissão estabelecer uma interlocução fecunda com as Ciências Sociais e, sobretudo, revelar quadros 
intelectuais respeitados no conjunto do corpo profissional e, também, em outras áreas do saber.

Ao tratar de "massa crítica", Netto (2006, p. 152), quer expressar "o conjunto de conhecimentos produzidos e acumulados por determinada ciência, disciplina ou área do saber". No caso do Serviço Social, por não ser ciência nem dispor de uma teoria própria, não tem sido entrave para os profissionais desenvolverem estudos investigativos, produzirem conhecimento.

Os autores que estudam a pesquisa, a produção do conhecimento e a pós-graduação no Serviço Social apreendem a indispensabilidade dessa articulação, a existência de um acúmulo teórico que se legitima na atualidade. Ademais, tais autores firmam a existência de uma particularidade ou especificidade histórica que advém da "agenda socioprofissional" (Faria, 2003). Em outras palavras, "a pesquisa é constitutiva e constituinte da prática profissional do Serviço Social, sendo determinada pela sua natureza interventiva e pela sua inserção histórica na divisão sociotécnica do trabalho" (Bourguignon, 2007, p. 45).

Sublinha-se ainda na pesquisa e na produção do conhecimento em Serviço Social a adoção de aportes teóricos e metodológicos críticos, inspirados no legado marxista, portanto, na perspectiva de ruptura com o conservadorismo profissional "capazes de propiciar a crítica radical das relações econômicas e sociais vigentes. À quebra do quase monopólio do conservadorismo político na profissão seguiu-se a quebra do quase monopólio do seu conservadorismo teórico e metodológico" (Netto, 2006, p. 152).

Decerto, há outras tendências que perpassam a pesquisa em Serviço Social já amplamente levantadas em produções anteriores, tais como: Setubal (1995 e 2007), Kameyama (1998, 2004a e 2004b), Faria (2003), Silva e Silva (2004), Abreu (2007), Sposati (2007), Bourguignon (2007 e 2008), Lara (2007 e 2008), Moraes (2013), dentre outras autoras. Desse modo, neste artigo, não se pretende esgotar a discussão sobre as tendências da pesquisa na área do Serviço Social nem tampouco no contexto do CNPq, que embora recente, a pesquisa nessa área espraia-se entre outras áreas do saber e agências de fomento nacional e internacional.

Essa realidade traduz-se na fragilidade da pesquisa do Programa de Serviço Social no CNPq a partir do parâmetro avaliativo adotado entre as reduzidas demandas encaminhadas pela área e as modestas demandas recomendadas. Esse quadro se materializa na insignificância orçamentária do Programa de Serviço Social, cuja 
participação é mínima em relação ao Programa de Psicologia que integra o mesmo comitê de assessoramento.

A predominância das análises investigativas em torno das políticas sociais - nas quais corporificam os espaços sócio-ocupacionais do assistente social conforma-se como uma tendência da pesquisa. Obviamente, essa tendência se repete na produção do conhecimento (livros, artigos, teses, dissertações) e nos programas de pós-graduação (áreas de concentração e linhas de pesquisa) do Serviço Social.

Outra tendência que predomina nas propostas investigativas do Serviço Social consiste na sua vinculação às múltiplas demandas sociais historicamente determinadas pela sociedade capitalista. Conforma-se como uma contratendência à hegemônica inovação tecnológica defendida pelo CNPq.

Por fim, revela-se a emersão de duas novas tendências adotadas por esse órgão de fomento que podem ser profícuas às pesquisas da área do Serviço Social: uma acena para o enfoque da educação e popularização de ciência e tecnologia, e a outra para interdisciplinaridade. Ambas as tendências são conhecidas e presentes nas pesquisas de Serviço Social. A primeira se expressa sobretudo na produção técnica dos pesquisadores e a segunda no campo das políticas sociais. Tais perspectivas expõem as exigências das agências de fomento e os desafios para os pesquisadores: conviver com o produtivismo, com o direcionamento de recursos e programas para áreas específicas, como Ciências sem Fronteiras; o direcionamento dos recursos para a área com base nas demandas e o comitê de Serviço Social compondo com o de Psicologia. Isso para apontar alguns dos grandes desafios.

Reconhece-se que embora a pesquisa no Serviço Social seja recente, muito já foi feito, com significativos avanços na produção do conhecimento na área. Entretanto, ainda há um longo caminho a ser percorrido na perspectiva de "conhecer e mudar a realidade, buscando respostas criativas, competentes e inovadoras frente aos desafios colocados pela realidade na qual a profissão se move" (Yazbek, 2004, p. 12).

Recebimento em: 14/8/2014 - Aprovação em: 21/8/2014 


\section{Referências bibliográficas}

ABREU, Marina Maciel. Pesquisa em Serviço Social: tendências na implementação das Diretrizes Curriculares. Temporalis, Brasília, n. 14, 2007.

ABREU, Marina Maciel; SIMIONATTO, Ivete. A situação da pesquisa em Serviço Social no Brasil 1990/1996. Cadernos ABESS, n. 1997.

AMMANN, Safira Bezerra. Produção científica do Serviço Social no Brasil. Serviço Social \& Sociedade, São Paulo, ano V, n. 14, 1984.

BAPTISTA, Myrian Veras. A produção do conhecimento social contemporâneo com ênfase no Serviço Social. Cadernos ABESS, São Paulo, n. 5, 1992.

(Org.). A prática profissional do assistente social: teoria, ação, construção de conhecimento. São Paulo: Veras Editora, 2009.

BOURGUIGNON, J. A. A centralidade ocupada pelos sujeitos que participam das pesquisas do Serviço Social. Textos \& Contextos, Porto Alegre, v. 7, n. 2, p. 302-312, jul./dez. 2008.

. A particularidade histórica da pesquisa no Serviço Social. Katálysis, Florianópolis, v. 10, número especial, p. 46-54, 2007. Disponível em: <file://C:/Users/Dell/Downloads/103214531-1-PB.pdf>. Acesso em: 15 jul. 2014.

BOURGUIGNON, Jussara Ayres. A particularidade histórica da pesquisa no Serviço Social. Tese (Doutorado em Serviço Social) — Pontifícia Universidade Católica, São Paulo, 2005.

CONSELHO NACIONAL DE DESENVOLVIMENTO CIENTÍFICO E TECNOLÓGICO. Membros do Comitê, 2010. Disponível em: $<$ http://www.cnpq.br/web/guest/membros-dos-comites>. Acesso em: 15 jul. 2014.

CONSELHO NACIONAL DE DESENVOLVIMENTO CIENTÍFICO E TECNOLÓGICO. Seminário de Avaliação das Bolsas de Produtividade em Pesquisa. Brasília. abr. 2013.

FARIA, Sandra. Produção de conhecimento e agenda socioprofissional no Serviço Social Brasileiro. Tese (Doutorado) — Programa de Estudos Pós-graduados em Serviço Social, São Paulo, 2003.

GUERRA, Yolanda. Investigação social e Serviço Social: novos processos de produção do conhecimento. In: CONGRESO LATINOAMERICANO DE ESCUELAS DE TRABAJO SOCIAL, 16., Anais..., Santiago do Chile, nov. 1998.

A pós-graduação em Serviço Social no Brasil: um patrimônio a ser preservado. Temporalis, Brasília, ano 11, n. 22, p. 125-158, jul./dez. 2011. 
GUERRA, Yolanda. Expressões do pragmatismo no Serviço Social: reflexões preliminares. Katálysis, Florianópolis, v. 16, número especial, p. 39-49, 2013. Disponível em: <http:// www.scielo.br/pdf/rk/v16nspe/04.pdf>. Acesso em: 20 jul. 2014.

IAMAMOTO, Marilda Villela. O Serviço Social em tempo de capital fetiche: capital financeiro, trabalho e questão social. São Paulo: Cortez, 2007.

KAMEYAMA, Nobuco. A trajetória da produção de conhecimentos em Serviço Social: avanços e tendências (1995 a 1997). Cadernos Abess, Associação Brasileira de Ensino de Serviço Social. Diretrizes Curriculares e Pesquisa em Serviço Social, São Paulo, n. 8, p. 33$76,1998$.

. O papel da pós-graduação e da pesquisa na formação profissional. Temporalis, Brasília, v. 8, 2004a.

. A construção da pós-graduação em Serviço Social no Brasil e Cone Sul e suas contribuições para a formação de docentes e produção do conhecimento: balanço crítico. In: OFICINA NACIONAL DA ABEPSS, Anais..., Florianópolis, ABEPSS, $2004 \mathrm{~b}$.

LARA, Ricardo. Pesquisa e Serviço Social: da concepção burguesa de ciências sociais à perspectiva ontológica. Katálysis, Florianópolis, n. 10, 2007.

. A produção do conhecimento em Serviço Social: o mundo do trabalho em debate. Tese (Doutorado) — Faculdade de História, Direito e Serviço Social da Unesp, Franca, 2008.

MENDES, Jussara Maria Rosa. A visibilidade de uma trajetória de 25 anos. Textos \& Contextos: perspectivas da produção do conhecimento em Serviço Social. Porto Alegre: PUC-RS/ Programa de Pós-graduação em Serviço Social, 2002.

; ALMEIDA, Bernadete de Lourdes Figueiredo de Almeida. Relatório do Julgamento pelo Comitê de Assessoramento de Serviço Social (CA-SS) das propostas submetidas às chamadas MCTI/CNPq/MEC/Capes n. 43/2013 (Ciências Humanas, Sociais e Sociais Aplicadas), Bolsas Especiais (país e exterior) e ARC. Brasília: CNPq, 2013a.

; __ Relatório do Julgamento das propostas submetidas à chamada pública do programa de bolsas de produtividade em pesquisa (PQ) 2013 pelo comitê de assessoramento de psicologia e Serviço Social (CA-PS) — Programa de Serviço Social. Brasília: CNPq, 2013b.

; __ . Relatório do Comitê de Assessoramento de Psicologia e Serviço Social (CA-PS) sobre a Reavaliação das Bolsas de Produtividade em Pesquisa (PQ) destinadas ao Programa de Serviço Social 2013. Brasília: CNPq, 2013c.

. A perspectiva da pesquisa multi e interdisciplinar no CNPq pelo comitê de assessoramento de psicologia e Serviço Social (CA-PS). Programa de Serviço Social. Brasília: CNPq, 2013d. 
MORAES, Carlos Antônio de Souza. A "viagem de volta": significados da pesquisa na formação e prática profissional do Assistente Social. Serviço Social \& Sociedade, São Paulo, n. 114, 2013.

NETTO, José Paulo. A Construção do Projeto Ético-Político do Serviço Social. In: MOTA, Ana Elizabete et al. (Orgs.). Serviço Social e saúde: formação e trabalho profissional. São Paulo: Fnepas, 2006.

NOBREGA, Mônica Barros; FONSECA, Cleomar Campos. Produção de conhecimento científico: a particularidade do serviço social brasileiro. Ser Social, Brasília, v. 12, n. 27, p. 165-188, jul./dez. 2010.

PRATES, Jane Cruz. A produção de conhecimentos e a contribuição dos periódicos para o amadurecimento teórico do Serviço Social. Textos \& Contextos, Porto Alegre, v. 12, n. 2. p. 213-220, jul./dez. 2013.

SETUBAL, Aglair Alencar. Pesquisa em Serviço Social: utopia e realidade. São Paulo: Cortez, 1995.

. Desafios à pesquisa no Serviço Social: da formação acadêmica à prática profissional. Katálysis, Florianópolis, v. 10, p. 64-72, 2007.

SILVA, José Fernando Siqueira. Pesquisa e produção do conhecimento em Serviço Social. In: Textos \& Contextos, Porto Alegre, v. 6, n. 2, 2007.

SILVA E SILVA, Maria Ozanira. A pós-graduação na área do Serviço Social no Brasil: contribuições das áreas de concentração e linhas de pesquisa dos programas para a construção do conhecimento. In: ENCONTRO NACIONAL DE PESQUISADORES EM SERVIÇO SOCIAL, 9., Anais..., Porto Alegre, 2004.

. Trinta anos da revista Serviço Social \& Sociedade: contribuições para a construção e o desenvolvimento do Serviço Social no Brasil. Serviço Social \& Sociedade, São Paulo, n. 100, p. 599-649, out./dez. 2009.

; CARVALHO, Denise Bontempo Birche. A pós-graduação e a produção de conhecimento no Serviço Social brasileiro. Revista Brasileira de Pós-Graduação, Brasília, v. 4, n. 8, 2007.

São Paulo: Cortez, 2005.

SIMIONATTO, Ivete. Os desafios na pesquisa e na produção do conhecimento em Serviço Social. Temporalis, Recife, n. 9, 2005.

; NOGUEIRA, Vera Maria Ribeiro. As demandas de pesquisas sobre proteção social no Mercosul: exigências para o Serviço Social. Katálysis, Brasília, v. 9, n. 2, 2006. 
SPOSATI, Aldaiza. Pesquisa e produção de conhecimento no campo do Serviço Social. Katálysis, Florianópolis, n. 10, p. 15-25, 2007.

YAZBEK, Maria Carmelita. Os caminhos para a pesquisa no Serviço Social. In: ENCONTRO NACIONAL DE PESQUISADORES EM SERVIÇO SOCIAL, 9., Porto Alegre: ABEPSS, dez. 2004.

Os fundamentos históricos e teórico-metodológicos do Serviço Social brasileiro na contemporaneidade. In: CONSELHO FEDERAL DE SERVIÇO SOCIAL. Serviço Social: Direitos Sociais e Competências Profissionais. Brasília: CFESS, 2006. 